\title{
Peran Penyuluh Agama dalam Program Desa Binaan Keluarga Sakinah Di Desa Dlingo
}

\author{
Nurkholis ${ }^{1}$, Istifianah ${ }^{2}$, A. Syafi'i Rahman ${ }^{3 *}$, \\ ${ }^{1}$ Kementerian Agama Kabupaten Bantul, ${ }^{2,3}$ Universitas Cokroaminoto Yogyakarta \\ *Penulis Koresponden, email: sunksam3@gmail.com
}

\begin{abstract}
Abstrak
Penyuluh Agama adalah Pegawai Negeri Sipil di bawah Departemen Agama yang bertugas, bertanggung jawab dan memiliki wewenang secara penuh untuk melakukan kegiatan bimbingan keagamaan dan penyuluhan pembangunan melalui bahasa agama. Penyuluh Agama menjadi salah satu pihak dalam pelaksanaan Program Desa Binaan Keluarga Sakinah (DBKS). Berdasar tugas dan wawenangnya sebagai PNS maka penelitian ini digelar sekaligus guna menemukan factor yang mendukung dan menghambat selama pelaksanaan program tersebut. Kajian kualitatif ini menyimpulkan bahwa mereka mendukung pelaksanaan DBKS tidak bergerak jauh lebih dari sesuai tugas dan Fungsinya sebagi penyuluh agama. Namun hal utama yang menghambat adalah kondisi social dalam pengetahuan agama, dan permasalah perkawinan dini menjadi penghambat meski dukungan kordinasi antar pihak yang terlibat dalam program tersebut di Dlingo sedah terjalin dengan baik. Maka program ini bisa dilanjutkan karena dampak positif dalam memotivasi masyarakat dalam beragama.
\end{abstract}

Kata Kunci: Penyuluh Agama, Desa Binaan Keluarga Sakinah, tugas dan wewenang

\begin{abstract}
Abtract
Religious counsellor are officials under the Ministry of Religion who are in charge, responsible and have full authority to carry out religious guidance and development education activities through religious language. The Religious Instructor is one of the parties in the implementation of the Sakinah Family Assistance Village Program (SFAF). Based on their duties and authority as civil servants, this research was held at the same time to find the factors that support and hinder the implementation of the program. This qualitative study concludes that they support the implementation of the DBKS not moving much more than according to their duties and functions as religious extension agents. However, the main thing that hinders the social conditions in religious knowledge, and the problem of early marriage becomes an obstacle even though the support for coordination between the parties involved in the program in Dlingo has been well established. So this program can be continued because of its positive impact in motivating people to have religion. Keywords: Religious counselor, Sakinah Family Assistance Village, duties and functions
\end{abstract}




\section{Pendahuluan}

Dalam hokum Indonesia Keluarga sakinah adalah keluarga yang dibina atas perkawinanyang sah, mampu memenuhi hajat hidup spiritual dan material secara layak dan seimbang, diliputi suasana kasih sayang antara anggota keluarga dan lingkungannya dengan selaras, serasi serta mampu mengamalkan ,menghayati dan memperdalam nilai-nilai keimanan dan akhlaq yang mulia. (Ditjen Bimas Islam dan Penyelenggaraan Haji Direktorat Urusan Agama Islam, 2005, 91).

Pengertian demikian tidak menyimpang dari pengertian undangundang yang lebih tinggi. Dengan rujukan kepada Undang-Undang RI Nomor 1 tahun 1974 tentang Perkawinan, Bab II Pasal 1. "Perkawinan adalah ikatan lahir batin antara laki-laki dan perempuan yang terbentuk dari perkawinan yang sah sesuai hukum yang berlaku dan bertujuan untuk mewujudkan kehidupan rumah tangga sejahtera yang diliputi rasa kasih sayang atau sakinah, mawaddah dan rahmah" (RI 1974).

Hal itu juga tidak bertentangan dengan pengertian istilahnya. Sulaiman mengartikannya dengan Keluarga sakinah berarti keluarga yang tenang atau keluarga yang tentram. Sebuah keluarga bahagia, sejahtera lahir dan batin, hidup cinta-mencintai dan kasih-mengasihi, di mana suami bisa membahagiakan istri, sebaliknya, istri bisa membahagiakan suami, dan keduanya mampu mendidik anak-anaknya menjadi anak-anak yang shaleh dan shalehah, yaitu anak-anak yang berbakti kepada orang tua, kepada agama, masyarakat, dan bangsanya. Selain itu, keluarga sakinah juga mampu menjalin persaudaraan yang harmonis dengan sanak famili dan hidup rukun dalam bertetangga, bermasyarakat, dan bernegara.(Sulaiman, Amin, dan Said 2019) Pendapat mereka ini mengikuti pengertian terdahulu. Marhijanto telah menjelaskannya lebih sederhana. keluarga yang harmonis, penuh kasih sayang antara suami istri, saling menghormati dan menghargai, mampu memberikan ketenangan dan meningkatkan ketaqwaan kepada Allah swt.(Marhijanto n.d.)

Guna mendukung keluarga sakinah tercipta dalam kehidupan keluarga muslim di Indonesia, Kementerian Agama telah menetapkan Program Pembinaan Keluarga Sakinah. Pengaturannya dalam Keputusan Menteri Agama RI No. 3 Tahun 1999 tentang Pembinaan Gerakan Keluarga Sakinah (Mawardi 2016). Penerbitan program ini bagian dari pembangunan ketahanan keluarga Indonesia yang dikendalikan oleh Kemenag.(Nasution dan Nasution 2017) 
Untuk melaksanakan gerakan tersebut telah dikeluarkan beberapa peraturan yang memberikan wewenang kepada aparat pemerintah wilayah Propinsi. Antara lain: Surat Edaran Dirjen Bimas Islam dan Urusan Haji No. D/PW.00/928, tertanggal 9 Maret 1999, perihal Pelaksanaan Pembinaan Gerakan Keluarga Sakinah kepada Kepala Kanwil Departemen Agama Propinsi Seluruh Indonesia. 3. Surat Edaran Dirjen Pembangunan Daerah Departemen Dalam Negeri No. 400/546/III/Banda, tertanggal Maret 1999, perihal Pelaksanaan Pembinaan Gerakan Keluarga Sakinah kepada Gubernur $\mathrm{KDH}$ TK.I Indonesia. Untuk tingkat selanjutnya telah diterbitkan Keputusan Dirjen Bimas Islam dan Urusan Haji No.D/71/1999 tentang Petunjuk Pelaksanaan Pembinaan Gerakan Keluarga Sakinah. (Nasution dan Nasution 2017)

Program Desa Bina Sakinah (DBKS) adalah salah bentuk pelaksanaannya di wilayah Propinsi Daerah Istimewa Yogyakarta. dalam instruksi Gubernur Kepala daerah No.10/INSTR/1993 pada tanggal 3 Agustus 1993 dijelaskan sebagai program rintisan Depag wilayah DIY yang bertitik tolak dari hasil MUSDA BP4 tahun 1992. Ditingkat desa pelaksanaanya melibatkan banyak pihak. mereka adalah kepala Desa dan didampingi Penyuluh Agama selaku tim pelaksana. Mereka dibantu oleh tim Pembina tingkat Kecamatan dari KUA sebagai program leader. Badan Penasihatan Pembinaan Dan Pelestarian Perkawinan (BP4) juga turut serta bersama para kader motivator dari warga desa(Tim Kementerian Agama Wilayah DIY 2012).

Sebagian besar masih memandang bahwa gerakan kelurga sakinah masih menjadi porsi utama dari tugas BP4. Perannya memang membentuk dan mewujudkan keluarga sakinah berdasarkan peraturan perkawinan dengan menggunakan metode pendampingan seperti penasihatan dan bimbingan. Rizkiya dan Marhamah (2017) menandai bahwa BP4 Kecamatan Kluet Utara dalam pembentukan keluarga sakinah, baik sebelum perkawinan (calon pengantin) maupun setelah perkawinan. perannya masih belum efektif dengan indicator konflik rumah tangga di wilayah wewenangnya masih terjadi. Meski ada hambatan keaktifan, Jamilah ( 2018) memuji keberhasilan BP4 dapat menyataukan kembali 4 perkawindan dari 5 kasus yang ditangani dengan tetap bertugas memberikan kursus pra nikah. Keaktifan juga menjadi sorotan Mawardi (2016) karena suami istri yang bermasalah jarang mendatangi BP4 dalam memecahkan masalah.

Keberhasilan Gerakan Keluarga Sakinah di tingkat pedesaan dipengaruhi juga dengan kordinasi antar lembaga (Ningsih dan As'ari 2019). 
Pelaksanaan DBKS merupakan peramsalahan public yang juga membutuhkan kordinasi antar lembaga pememrintah maupun organisasi keislaman yang siap bergerak lebih mobile. Penyuluh Agama menjadi agen penting dalam hal ini. Penyuluh Agama adalah Pegawai Negeri Sipil di bawah Kemenag yang bertugas, bertanggung jawab dan memiliki wewenang secara penuh untuk melakukan kegiatan bimbingan keagamaan dan penyuluhan pembangunan melalui bahasa agama (Bimas Islam 2017). Tugas Pokoknya, mengusahakan dan mengembangkan kegiatan bimbingan atau penyuluhan Agama dan pembangunan melalui bahasa agama. Lembaga ini kemudian memiliki fungsi informatif dan edukatif, serta konsultatif termasuk advokatif (Pranowo 2005).

Penyuluh agama kemudian mempunyai posisi unik. Satu sisi adalah pelaku komunikasi public yang harus melayani masyarakat terhadap permasalahan keagamaan yang melibatkan pemerintah dan warganya. Ia memiliki kewajiban yang sama seperti aparat pemerintah dalam komunikasi public (Muthmainnah et al. 2019; Supratman et al. 2019). Ia juga dituntut menguasai pengetahuan agama guna mendorong kesadaran agama umat di berbagai aspek kehidupan (Arifudin et al. 2019).

Pengaturan demikian sesuai dengan Keputusan Menteri Negara Koordinator Bidang Pengawasan Pembangunan dan Pendayagunaan Aparatur Negara Nomor 54/Kep/MK.WASPAN/9/1999 (Bimas Islam 2012). Berdasar peraturan tersebut, penelitian ini digelar untuk mengetahui peran penyuluh agama dan factor pendukung dan penghambatnya dalam pelaksanaan DBKS di Desa Dlingo Kecamatan Dlingo Kabupaten Bantul Propinsi DIY.

\section{Metode}

Penelitian menggunakan pendekatan deskriptif kualitatif. Data yang telah dikumpulkan kemudian dianalisa data dengan menggambarkan data dalam bentuk kalimat. Caranya mengombinasilan pola induktif, yaitu menarik kesimpulan umum berdasarkan data yang bersifat khusus, dan deduktif yang menarik kesimpulan berdasarkan data-data yang bersifat khusus. Penelitian menggunakan tiga teknik pengumpulan data, dokumentasi, observasi dan wawancara mendalam. Dokeumentasi terutama berhubungan dengan landasan hokum serta dokumen lainnya yang berkaitan dengan pelaksanaan DBKS di Wilayah Dlingo. Observasi ditujukan pada pengamatan kegiatan pelaksanaan DBKS. Wawancara mendalam ditujukan kepada para penyuluh yang bertugas serta kepala KUA Kecamamatan Dlingo selaku pimpinan pelaksana. Hasilnya dibahas setelah kumupulan data 
disusun dan diklarifikasi dan selanjutnya di analisis dan diinterpretasikan dalam bentuk kalimat yang sederhana dan mudah dipahami sehingga data tersebut dapat diambil pengertiannya untuk mencapai kesimpulan penelitian.

\section{Pelaksanaan Progam DBKS Di Dlingo}

Dasar hokum program DBKS telah ditetapkan secara kuat. Intruksikan Gubernur No.10/INSTR/1993 pada tanggal 3 Agustus 1993. Kententuan tersebut menjadi eja wantah dari amanat dalam pasal 4 UU No.10 tahun 1992 tentang Perkembangan Penduduk Dan Pembangunan Keluarga Sejahtera yang juga menjadi dasar ketahanan keluarga di Indonesia (Hisyam et al. 2019). Program tersebut lahir sebagai tindak lanjut dari hasil MUSDA BP4 tahun 1992 (Tim Departemen Agama Wilayah Propinsi DIY n.d.:14).

Sebelum pelaksanaan diadakan perencanaan melalui tahapan rintisan. Awalnya Penetapan DBKS oleh Bupati diiringi pembentukan tim Pembina tingkat kecamatan oleh Camat. Selanjutnya Pembentukan tim pelaksana DBKS tingkat Desa, oleh Lurah.(Tim Departemen Agama Wilayah Propinsi DIY n.d.). Dari rujukan yang sama juga diketahui bahwa operasionalisasi DBKS ditandai dengan rekrutmen Kader Motivator dan Pembina keluarga sakinah yang diambil dari setiap dasa wisma 1 kader yang kemudian tergabung dalam korp penasihat. Pelaksananya adalah kepala Desa dan didampingi Penyuluh Agama KUA Kecamatan selaku tim pelaksana Program desa binaan (DBKS ) dibantu oleh tim Pembina tingkat Kecamatan. Mereka ini kemudian diberi pembekalan tentang; (a)Pembinaan kehidupan beragama dalam keluarga, (b)Undang-undang No.I tahun 1974 tentang perkawinan dan hukum munakahat. (c)Pembinaan agama di pedesaan. (d) Pembinaan kerukunan hidup beragama. (e) Dan pembinan keluarga sejahtera. Selain itu juga, para peserta juga mendapatkan metode penyuluhan/ pembinaan/ penasihatan. Penyelenggara penataran/ pembekalan adalah BP4 bekerja sama dengan LKMD (Khususnya seksi Agama dan PKK) di bawah koordinasi Kepala Desa/lurah setempat.

Kader motivator kemudian melaksanakan pendataan calon warga binaan yang didampingi oleh penyuluh agama dari KUA Kecamatan Dlingo dengan sasaran Kepala Keluarga Muslim atau kelompok Pengajian para ibu termasuk kader PKK. Wilayah binaannya kemudian dibagi menjadi 2 kelompok per dukuh, yaitu: Dusun Koripan I dan II; Dusun Pokoh I dan II; Dusun Dlingo I dan II, Dusun Pakis I dan II serta Dusun Kebosungu I dan II.

Adapun pada pelaksanaan kegiatan, berdasarkan pada pola orasionalisasi pembinaan keluarga sakinah, pihak KUA Kecamatan Dlingo 
beserta setgas DBKS Desa Dlingo telah mengadakan berbagai upaya tentang pembinaan. Di antara pembinaanya adalah: melalui pengajian rutin tingkat Desa, pembinaan kepada para kader DBKS yang bertempat gedung pertemuan Desa Dlingo stiap tiga bulan 1 kali sekaligus monitoring hasil triwulan, serta kunjungan rutin pihak KUA ke Desa Dlingo yang dilakukan satu kali dalam sebulan.

Kegiatan penting dalam DBKS di Dlingo adalah Program pengajian rutin tingkat pedukuhan pada umumnya dilakukan setiap satu minggu sekali di setiap pedukuhan. Waktu pelaksanaan pengajian dilakukan dengan mengikuti jadwal yang telah ada. Materi tentang domestic keluarga dalam perspektif fikih dan hokum Indonesia yang berlaku serta pengaruhnya dalam kehidupan bermasyarakat. Karena itu, banyak yang mengatakan hal demikian sebagai bagian dari sosialisasi bagian dari peran KUA dalam pencegahan pernikahan usia dini (Wafiq dan Santoso 2017). Maka mereka juga memiliki kewajiban untuk mensosialisasikan administrasi perwakafan tanah (Sukarno et al. 2019)

Terlepas dari bagaimana pelaksanaan Program DBKS di Desa Dlingo, ada beragam pendapat dalam menyikapi adanya program DBKS di Desa Dlingo bahwa program kerja yang dilakukan oleh KUA tentang keluarga sakinah sangat diperlukan, karena bersama-sama memberikan motivasi terhadap masyarakat khususnya keluarga muslim untuk mewujudkan perkawinan yang sakinah, mawaddah dan rahmah. Sementara pengetahuan masyarakat tentang cara menghadapi kehidupan berkeluarga terutama berdasarkan agama sangatlah kurang.

Dalam pola operasional pembinaan kader Keluarga Sakinah maka pihak KUA mengadakan penyuluhan tiap tiga bulan sekali diadakan pertemuan dengan para kader yang dilakukan dibalai Desa Dlingo. Tujuannya adalah untuk evaluasi dan memotivasi para kader supaya konsisten dan tekun dalam menjalankan tugasnya. Adapun evaluasi menyeluruh juga dilakukan oleh lembaga yang sama menyangkut menyangkut administrasi dan kordinasi program tersebut.

\section{Peran Penyuluh}

Peran seseorang penyuluh sangatlah penting di dalam suatu masyarakat luas, karena dari berbagai banyaknya masyarakat tentunya tingkat pengetahuan dan karakter satu sama lain tidak sama. Dari penyuluhan dan pembinaan di dalam masyarakat, seseorang penyuluh mempunyai kurikulum yang sesuai dengan sasaran dari program di dalam masyarakat. 
Pada intinya penyampaian bahan penyuluhan dan pembinaan tergantung dari kelompok binaan, karena tidak hanya satu warga binaan kelompok saja yang dilakukan oleh para penyuluh KUA Kecamatan Dlingo Kabupaten bantul. Setiap seorang penyuluh dengan penyuluh lain menangani program yang berbeda-beda karena tugas dan peran seseorang penyuluh agama juga sangat banyak.

Penyuluh yang membidangi program Desa binaan keluarga sakinah ini dilakukan penyuluh secara bergantian, karena dalam melakukan penyampaian bahan penyuluhan berbeda-beda pula. Dan setiap melakukan penyuluhan akan diadakan pelaporan yang disampaikan kepada tingkat kementerian Agama Kabupaten. Selain itu juga bahan yang digunakan untuk penyampaian penyuluhan juga beragam, misalnya dengan metode ceramah , metode sorogan, juga metode musyawarah atau Bahsul Masai'il. Dalam penyampaian penyuluh sebelumnya bahan yang akan disampaikan terlebih dahulu dikonsep dan ditulis secara terperinci yang akan disampaikan kepada kelompok pengajian karena sebagai laporan seseorang penyuluh dari apa yang telah dilakukan terhadap program tersebut.21

Proses penyuluhan DBKS) di desa Dlingo diupayakan melalui tiga cara, yakni; 1) Menciptakan suasana atau iklim dan keadaan yang memungkninkan potensi masyarakat untuk berkembang dan menjadi warga masyarakat yang sakinah. 2) Memperkuat potensi yang dimiliki oleh masyarakat dengan menerapkan langkah-lanhkah nyata, manampung berbagai masukan dan arahan dari penyuluh, dan menjalankan apa yang harus dijalankan sebagai keluarga yang sakinah. 3) Melindungi dan membina masyarakat yang belum mengerti tentang peran dan fungsi di dalam keluarga, karena kurangnya pengetahuan yang masih rendah. Langkah pertama yang kelompok warga desa binan keluarga sakinah yakni member pembekalan atau pembinaan ini dilaksanakan pada saat penyuluhan dilakukan oleh Penyuluh KUA di suatu kumpulan atau pertemuan rutin warga DBKS desa Dlingo.

Penyuluhan dan pembinaan suatu masyarakat merupakan hal penting dalam upaya memajukan suatu penduduk masyarakat, gagasan dasar tersebut kemudian dijabarkan dalam kegiatan-kegiatan pengembangan kesadaran, pengetahuan dan ketrampilan dalam rangka pemenuhan kebutuhan praktis dan kepentingan bagi pembangunan masyarakat desa Dlingo.

Dari program yang sudah ada, penyuluh agama islam mempunyai sasaran, ialah kelompok-kelompok warga binaan yang terdiri dari berbagai latar belakang yang berbeda dari social, budaya, pendidikan, kelompok masyarakat dan keluarga binaan. Pemetaan kelompok sasaran penyuluhan 
agama penting dilakukan untuk memudahkan dalam memilik metode bahasan yang akan disampaikan, karena tidak semua tingkat pengetahuan warga binaaan sama disebabkan perbedaan usia, daya tangkap pemahaman yang disampaikan penyuluh. Berdasarkan sasaran masyarakat umum, terdiri dari :

Peran Penyuluh Agama dalam DBKS kemudian mempunyai tugas pokok yakni; mengumpulkan data identifikasi potensi wilayah atau kelompok sasaran, menyusun rencana kerja operasional serta mengmpulkan bahan materi bimbingan dan penyuluhan serta pembinaan. Mereka juga bertugas mengimplementasikannya dalam berbagai sarana seperti bentuk poster, media elektronik dan juga bisa di tekskan. Tugas selanjutnya adalah Melaksanakan bimbingan dan penyuluhan melalui tatap muka kepada masyarakat warga binaan di pedesaan dalam majelis ta'lim dan ceramah dan pengajianpengajian PKK atau yang lain yang berkaitan dengan program desa binaan. Mereka juga Melakukan konsultasi secara kelompok atau diskusi di dalam program penyuluhan yang berguna untuk memajukan berpikir yang maju kepada masyarakar pedesaan.

Dalam analisis dan evaluasi terhadap pengalaman penyuluhan dan pembinaan masyarakat dapat dilihat dari sisi aspek ruang lingkup penyuluhan mencakup moral spiritual tetapi juga mencakup tentang penyampaian dan pemberian pencerahan terhadap keluarga. Dalam memberikan penyuluhan dan pembinaan seorang penyuluh adalah tsebagai tempat berkonsultasi masyarakat binaan terhadap permasalahanpermasalahan yang mereka alami di dalam sebuah keluarga sebatas masalah tentang keluarga, karena jika konsultasi permasalahan keluarga yang lain seperti pembinaan keluarga tentunya sudah menjadi wewenang pejabat lain yakni tugas BP4 KUA. Ini hanya permasalahan yang dihadapi oleh keluarga warga binaan.

Dengan demikian, penyuluhhan dalam visi keluarga sakinah di desa Dlingo Kecamatan Dlingo Kabupaten bantul, dapat dirumuskan bahwa penyuluh berperan di dalam program tersebut yang sistematis yang berbasis pada perencanaan yang lengkap, menyeluruh yang disusun secara berpusat, disamping proses alamiah yang melibatkan semua pihak atau suatu proses perubahan akhir pada keluarga yang tidak lain adalah proses menuju keluarga yang sakinah dan sejahtera. Perspektif penyuluhan yang seperti inilah yang menjamin terwujudnya peran penyuluh agama terhadap masyarakat melalui program desa binaan dapat berlanjut dan terus menerus.

Pemahaman dalam visi keluarga sakinah dapat disimpulkan sebagian kemandirian subyak pembinaan dan penyuluhan terhadap warga masyarakat 
binaan di masyarakat yang dapat mencakup orang perorang, kelompok dan warga binaan dalam hal Pengelolaan potensi dan sumber daya manusia untuk memenhui kebutuhan dan kesejahteraan keluarga termasuk Pemeliharaan kelestarian fungsi dan kualitas keluarga

Mereka juga mensosialisasi Batasan umur minimal bagi pasangan suami istri ini dimaksudkan untuk menjaga kestabilan keluarganya yagar kelak. Karena seorang pemuda yang telah berumur 25 tahun, ditinjau dari segi pendidikan diperkirakan sudah sarjana jika melanjutkan ke jenjang yan lebih tinggi dan menurut kedewasaan sudah matang jiwanya secara lahir dan batin. Bila ditinjau dari segi kemasyarakatan sudah mampu bergaul dengan orang dan bila ditinjau dari segi kemampuan ekonomi, maka setidaknya sudah bias mandiri dengan berusaha berfikir secara dewasa. Demikian pula bila calon istri sudah berumur dua puluh tahun keatas, tentunya juga mampu menangani hal-hal tersebut diatas (Marhijanto n.d.).

Melalui upaya dakwah bilisan hal pembinaan dan penyuluhan masyarakat desa melalui program Desa binaan keluarga sakinah (DBKS) kemudian dapat menfokuskan diri pada pembinaan di dalam kelompok masyarakat binaan karena seseorang penyuluh membina keluarg sesuai dengan ajaran agama islam.

Pembinaan dan penyuluhan komunitas mengajukan suatu praktik penyuluhan yang mengutamakan partisipasi-partisipasi dari masyarakat warga desa binaan itu sendiri. Hal itu dilakukan oleh para penyuluh KUA Kecamatan Dlingo dalam proses penyuluhan terhadap masyarakat desa Dlingo adalah suatu pembangunan kesadaran guna meningkatkan sumber daya warga binaan desa Dlingo yang berkualitas dan mampu menghadapi tantangan masa depan dan yang akan datang.

Dari pola penyuluhan komunitas pedesaan tersebut, maka watak komunitas yang diharapkan sebagai output adalah komunitas demokrasi dan memiliki kebebasan serta kemampuan untuk menentukan nasibnya atas dasar kekuatan sendiri. Penyuluhan dalam visi kehidupan keluarga sakinah memiliki beberapa prinsip. 1) Tujuan penyuluhan tidak hanya saja diarahkan untuk menolong suatu komunitas dalam upaya memecahkan kehidupan social. Keluarga keseharian, namun lebih jauh mengarah kepada upaya mewujudkan perubahan social suatu masyarakat di dalam keluarga agar lebih sejahtera dan menjadi keluarg yang sakinah, mawadah wa rahmah. 2) Penyuluhan dan pembinaan masyarakat mestinya dapat membawa masyarakat binaan, karena peran penyuluh berperan utama dalam melaksanakan transformasi social serta jadi pedoman penyuluh digunakan sebagai pedoman pencerahan dalam membinan masyarakat untuk mencapai 
tujuan desa binaan keluarga sakinah (DBKS). Berarti secara tidak langsung memberikan pembinaan dan pencerahan kepada mereka agar mampu maghadapi upaya membangun visi terwujudnya dari masyarakat yang sejahtera. 3) Penyuluhan terhadap masyarakat binaan dilakukan dengan cara mensertakan cara belajar yang sederhana, yang menyempurnakan secara terus menerus (berulang- ulang )dalam pemahaman lewat pengalaman.(Pranowo 2005)

DBKS bagi penyuluh agama adalah sebuah organisasi yang bergerak di bidang social public. Tujuannya untuk mensejahterakan masyarakat dengan jalan mengingat sumber daya yang ada agar lebih berkualitas dan berdayaguna. upaya lainnya mengembangkan taraf kesejahteraan masyarakat dalam suatu wadah yakni dalam program desa binaan keluarg sakinah ini.

Dalam pemberian pembinaan dan penyuluhan adalah kegiatan penyuluh agama telah memberikan arahan dan binaan terhadap permasalahan kelompok binaan atau masyarakat binaan dalam pembangunan keluarga untuk menuju keluarga sakinah dan sejahtera. Juga seseorang penyuluh keagamaan dapat membantu memecahkan permasalahan di dalam masyarakat, misalnya permasalahan tentang kedudukan keluarga, tanggung jawab sebagai suami, tanggung jawab sebagai istri dan juga permasalahan rumah tangga yang lain.(Pranowo 2005)

\section{Faktor Pendukung dan Penghambat}

Faktor pendukung pelaksanaan DBKS di desa Dlingo. Keaktifa semua pihak termasuk dalam berkordinasi satu sama lain. Kemudahan dan keragaman kegiatan saebagi sarana penyampaian materi. Kesemaan pandangan tentang keluarga sakinah terhadap semua pihak termasuk keluarga binaan karena kesamaan keyakinan Islam. Kesadaran para masyarakat warga binaan untuk meningkatkan kemajuan serta untuk membentuk keluarga yang lebih menjadi sakinah dan sejahtera. Penggunaan teknologi informasi juga mempermudah variasi sosialisasi kelurga sakinah.

Meski demikian beberapa faktor penghambat juga ditemukan. keTerbatasan sumber daya manusia yang diperlukan untuk melaksanakan kegiatan penyuluhan tersebut dari masyarakat sendiri. Masih banyak warga yang merasa cukup dengan kemampuan yang sudah ada (nrimo) sehingga kegiatan pembinaan kurang maksimal. Tingkat pemahaman masyarakat atau warga binaan yang berbeda dikarenakan kondisi tingkat pendidikan yang tidak sama. Pengelompokan usia keluarga binaan juga belum ditata sehingga penyampaian apa yang telah dilakukan oleh penyuluh kurang maksimal. 


\section{Kesimpulan}

Peran seseorang penyuluh sangat penting di dalam warga binaan keluarga sakinah di desa Dlingo, karena dari berbagai bentuk dan kondisi masyarakat yang berbeda- beda tingkat kemampuan dan karakternya, maka oleh karena itu seseorang penyuluh tentunya mempunyai program yang sesuai dengan sasaran didalam warga binaan yang sudah mempunyai tujuan atau menurut kurikulum yang sesuai apa yang akan disampaikan kepada warga binaan. Para Penyuluh dalam mendukung pelaksanaan DBKS di desa Dlingo tidak bergerak jauh lebih dari sesuai tugas dan Fungsinya sebagi penyuluh dalam Keputusan Menteri Negara Koordinator Bidang Pengawasan Pembangunan dan Pendayagunaan Aparatur Negara Nomor 54/Kep/MK.WASPAN/9/1999.

DBKS hendaknya dapat dilestarikan dan dilanjutkan karena dampak positif dalam memotivasi masyarakat dalam beragama. Penyelenggaraan DBKS menuntut koordinasi terus sehingga mendapat solusi atau jalan keluar dalam penyelesaian masalah di dalam masyarakat warga binaan dapat terjawab dan berjalan dengan cepat dan lancer. Peran serta masyarakat banyak dan kelompok binaan sangat diperlukan dalam penyuluhanpenyuluhan ditingkat masyarakat, agar terbentuk sebuah keluarga yang mandiri dan sejahtera menurut ajaran Agama islam dan terbentuk keluarga yang skainah, mawadah warahmah.

\section{Daftar Pustaka}

Arifudin, Wahyu Amin, Nurul Fatihah, Ahmad Echsan, Lailatul Maftuhah, Difla Nadjih, dan Agus Pandoman. 2019. "Kesadaran Beragama Pelaku Pariwisata di Kawasan Malioboro." Nuansa Akademik: Jurnal Pembangunan Masyarakat 4(2):117-32.

Bimas Islam. 2012. Petunjuk Teknis Pelaksanaan Jabatan Fungsional Penyuluh Agama. Jakarta: Kementerian Agama RI.

Bimas Islam. 2017. Buku Pedoman Penyuluh Agama Islam Non PNS. Jakarta: Kementerian Agama RI.

Hisyam, Muhammad Ridho, Suyanto, Muhammad Sadzili, Zainul Arifin, dan Ahmad Syafi'i Rahman. 2019. "Peran Anggota Keluarga Berketahanan Dalam Perspektif Quran." Ulumuddin: Jurnal Ilmu-ilmu Keislaman 9(2):171-86.

Jamilah, Fitrotin. 2018. "Peranan (BP4) Dalam Membina Keluarga Sakinah Dan Penyelesaian Penyelisihan Perkawinan Islam Role (BP4) In Developing The Family Of Sakinah And Settlement Of Islamic Marriage Differences." AL-FIKRAH: Jurnal Studi Ilmu Pendidikan dan Keislaman 2(1):45-59.

Marhijanto, Kholillah. n.d. Menciptakan keluarga Sakinah. Gresik: Bintang Pelajar.

Mawardi, Marmiati. 2016. "Keluarga Sakinah: Konsep \& Pola Pembinaan." 
International Journal Ihya' 'Ulum al-Din 18(2):253-67. doi: 10.21580/ihya.17.2.1739.

Muthmainnah, Muthmainnah, Zainul Arifin, Toto Hermawan, Barid Barid, dan Akhmad Muhaini. 2019. "Analisis Implementasi Program Gerakan Arah Kiblat 1000 Masjid/ Mushola di Kabupaten Sleman." Nuansa Akademik: Jurnal Pembangunan Masyarakat 4(2):91-104.

Nasution, Khoiruddin, dan Syamsruddin Nasution. 2017. "Peraturan dan Program Membangun Ketahanan Keluarga : Kajian Sejarah Hukum." Asy-Syir'ah 51(1):1-23.

Ningsih, Aprilia, dan Hasim As'ari. 2019. "Pola Pembinaan Kampung Binaan Keluarga Sakinah Di Kabupaten Siak (Studi Implementasi Peraturan Bupati Nomor 14 Tahun 2016 Di Kecamatan Siak)." Jurnal Online Mahasiswa (JOM) Bidang Ilmu Sosial dan Ilmu Politik 6(1):1-15.

Pranowo, H. M. Bamban. 2005. Petunjuk teknis Jabatan Penyuluh Agama Islam. Departemen Agama Wilayah Propinsi DIY.

RI. 1974. Undang-Undang RI Nomor 1 tahun 1974 tentang Perkawinan.

Rizkiya dan Santi Marhamah, Miffa. 2017. "Upaya Badan Penasehatan, Pembinaan Dan Pelestarian Perkawinan (BP4) Dalam Pembinaan Dan Pelestarian Perkawinan." Al-Mursalah Jurnal Hukum Islam 3(2).

Sukarno, Sukarno, Supriyono Supriyono, Miftachul Alfin, Fattah Setiawan, Moh. Shofiyul Huda MF, dan Busyro Busyro. 2019. "Analisis Implementasi Wakaf Tanah di Kecamatan Pandak Kabupaten Bantul." Nuansa Akademik: Jurnal Pembangunan Masyarakat 4(2):133-44.

Sulaiman, Syamsir, Muliaty Amin, dan Nurhidayat Muhammad Said. 2019. "Pemahaman Masyarakat Kecamatan Rappocini Tentang Keluarga Sakinah." Jurnal Diskursus Islam 7(1):53-69. doi: 10.24252/jdi.v7i1.10083.

Supratman, Bawa, Fatah Nashir, A. S. Rahman, Zainul Arifin, dan Cipto Sembodo. 2019. "Pelaksanaan Jaring Aspirasi Sebagai Komunikasi Publik Pemerintah Daerah Kabupaten Kulon Progo." Nuansa Akademik Jurnal Pembangunan Masyarakat 4(1):1-16.

Tim Departemen Agama Wilayah Propinsi DIY. n.d. Petunjuk Teknis dan Pola Desa Binaan Keluarga Sakinah. Yogyakarta: Departemen Agama Wilayah Propinsi DIY.

Tim Kementerian Agama Wilayah DIY. 2012. Pola Pembinaan Keluarga Sakinah dan Desa Binaan Keluarga Sakinah (DBKS). Yogyakarta: Kementerian Agama Wilayah DIY.

Wafiq, Ahmad, dan F. Setiawan Santoso. 2017. "Upaya Yuridis Dan Sosiologis Kantor Urusan Agama Dalam Pencegahan Pernikahan Usia Dini." Ulumuddin: Jurnal Ilmu-ilmu Keislaman 7(1):17-30. 